\title{
SIPHON BREAKER DESIGN REQUIREMENTS PROGRESS REPORT
}

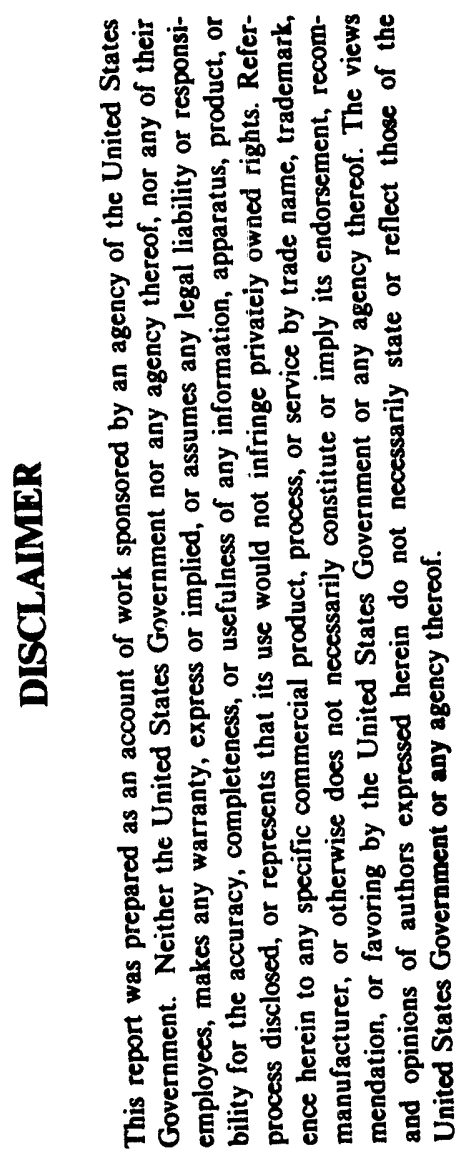

\author{
PRINCIPAL INVESTIGATORS: \\ D.T. NEILL, P.E. \\ PROFESSOR OF ENGINEERING \\ A.G. STEPHENS \\ ASSOCIATE PROFESSOR \\ DIRECTOR OF PH.D. PROGRAM \\ IDAHO STATE UNIVERSITY \\ COLLEGE OF ENGINEERING \\ POCATELLO, ID 83209
}

SPONSORED BY:

USA DEPARTMENT OF ENERGY

NUCLEAR ENGINEERING RESEARCH PROGRAM

DE-FG07-88ER12820 


\section{INTRODUCTION}

The Siphon Breaker Design Requirements Project was intended to provide some experimental data on siphon flow effects. In addition, the system was to be modeled with the RELAP code and the predicted and measured performances compared.

\section{EOUIPMENT}

The experimental system, outlined on Figure 1 , consists of a 500-galion upper tank, a 4-inch downcomer pipe, a lower catch tank, a return pump and associated piping. The downcomer pipe is made of 4-inch clear acrylic pipe so the flow patterns could be observed and video taped during the test runs.

The anti-siphon inlet air line is connected to the apex of the water piping. The air line is equipped with a turbine meter to measure the air flow, an orifice assembly to "control" the airflow and an electric actuated ball valve which permits starting and stopping the air flow. The water piping between the upper tank and the apex is equipped with a turbine flow meter and an electric actuated ball valve. That valve is used to isolate the "upper" tank so the apex of the piping can be completely filled before siphon flow is started.

The downcomer pipe is also equipped with a manually operated ball valve which is closed while the downcomer piping is filled and vented. This valve is used to start the siphon flow for a test run. The downcomer pipe discharges vertically upward through an orifice assembly. The siphon water flow is "controlled" by changing an orifice in that assembly.

Additional instruments were provided to measure the liquid level in the upper tank, the vacuum in the apex pipe, the pressure differential between the apex and the discharge orifice, the pressure at the discharge orifice, and two differential pressures located just below the mid-level of the downcomer pipe. Each of those dp transmitters covers a 6-foot length of pipe and the two lengths are adjacent to each other. We planned to employ a nuclear densitometer in the middle of each dp transmitter length but we have not yet completed their installation.

A PC based data logger was used to record all the measurements diring a test run. A new set of data were recorded every 2 to 3 seconds and each recorded data valve was the average of five individua.I readings made over a 1 to 2 second log-time. 


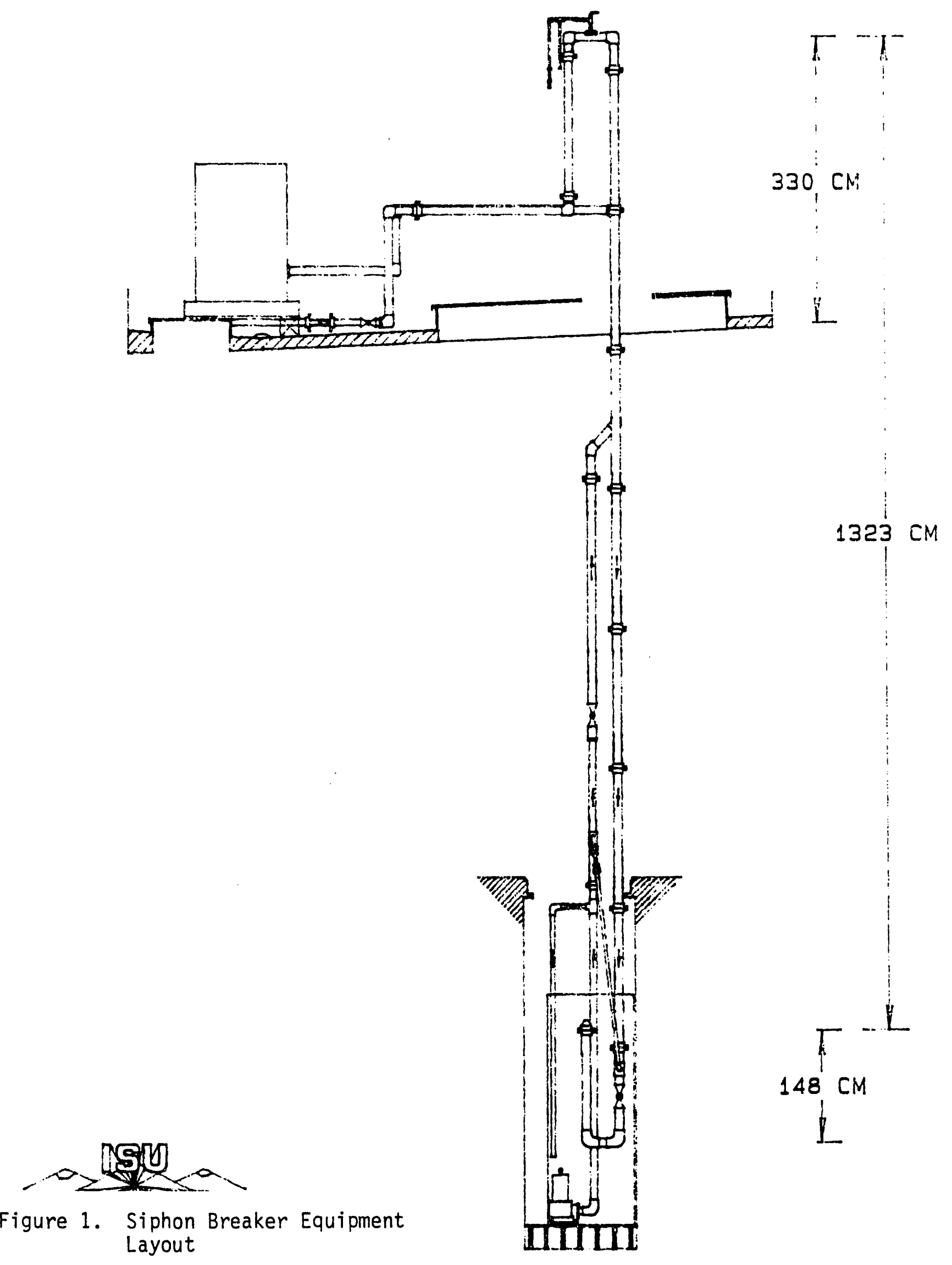




\section{RESUITS}

Many of our test runs were video taped. We have edited the best of these recordings into a 20-minute presentation which pretty well covers the range of our tests to date. The major features shown on the tape are the water fall which forms at the top of the downcomer during low flow runs; the shape of the "air bubble" at the air inlet in the apex pipe; and the chaotic 2-phase flow in the downcomer during medium and high flow runs.

We have not yet persuaded REIAP to give us any results we can compare to the test runs. However, new, fresh offerings have been made to the software Gods and a favorable output is anticipated any day now.

Figures 2-10 present a few typical plots of test results which, we think, illustrate a number of interesting features of siphon breaker performance. Figures 2,3 and 4 present upper tank water volumes during the WF $3 \times$. xxx test series. The first digit in the test name, a 3 for these tests, indicates that the downcomer discharge orifice diameter was $21.1 \mathrm{~mm}(0.83$ inches). The second digit in the test name indicates the air line orifice diameter: a I corresponds to a $2.4 \mathrm{~mm}(0.094$ inches) diameter;a 2 corresponds to a $3.4 \mathrm{~mm}$ (0.134 inches) diameter; and a 3 corresponds to a 4.4 $\mathrm{mm}(0.173$ inches) diameter. The final three digits after the period indicate the run number for a given test series.

The adjusted time scale on all the plots is zeroed at the time we opened the anti-siphon valve to allow air into the apex pipe. The flow values plotted before adjusted time zero are for water flow only, after that they reflect 2-phase flow. We opened the anti-siphon valve at several different levels in the upper tank. (The upper tank cross sectional area was almost exactly one square meter so a 100 liters of upper tank volume is equivalent to $10 \mathrm{~cm}$ of elevation.) The lower the water level in the upper tank, the greater the apex vacuum and the higher the inlet air flow. Consequently, the adjusted time required to break the siphon is reduced slightly as the water level at adjusted time zero is lowered. Obviously the water volume drained after the anti-siphon valve is opened decreases very significantly as the air orifice diameter increases. 


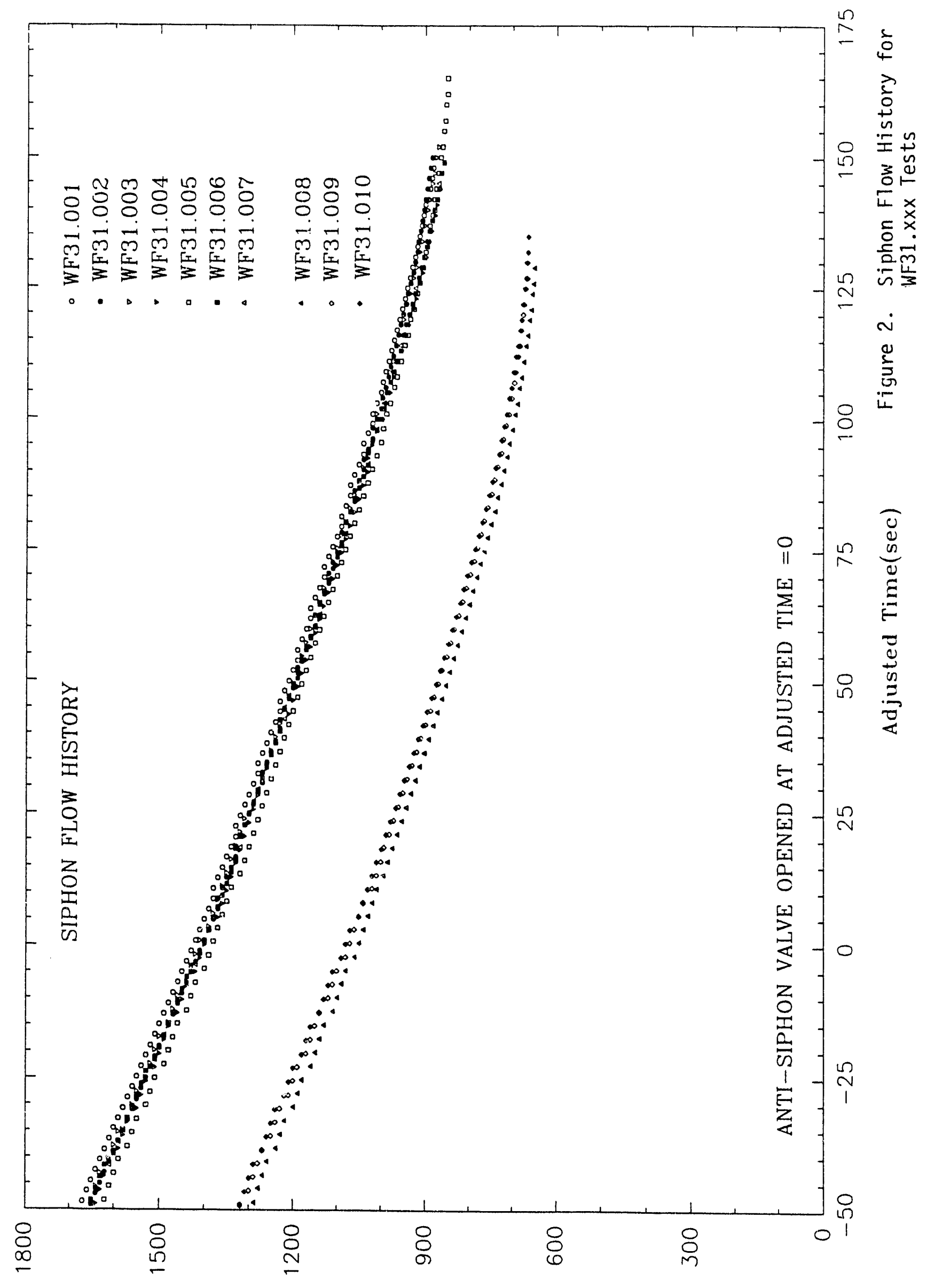

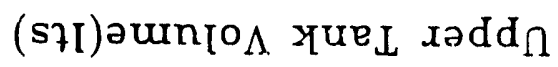




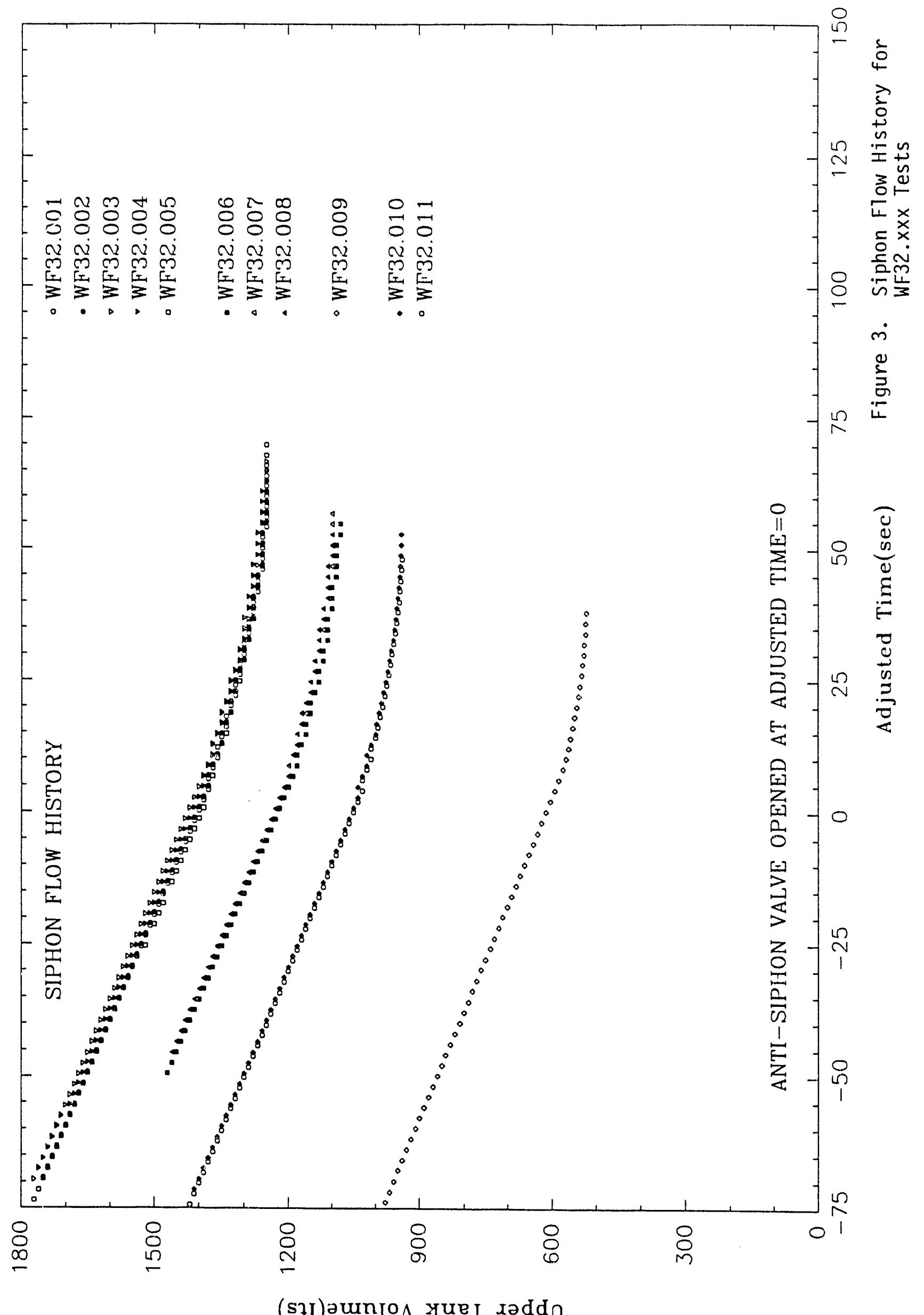




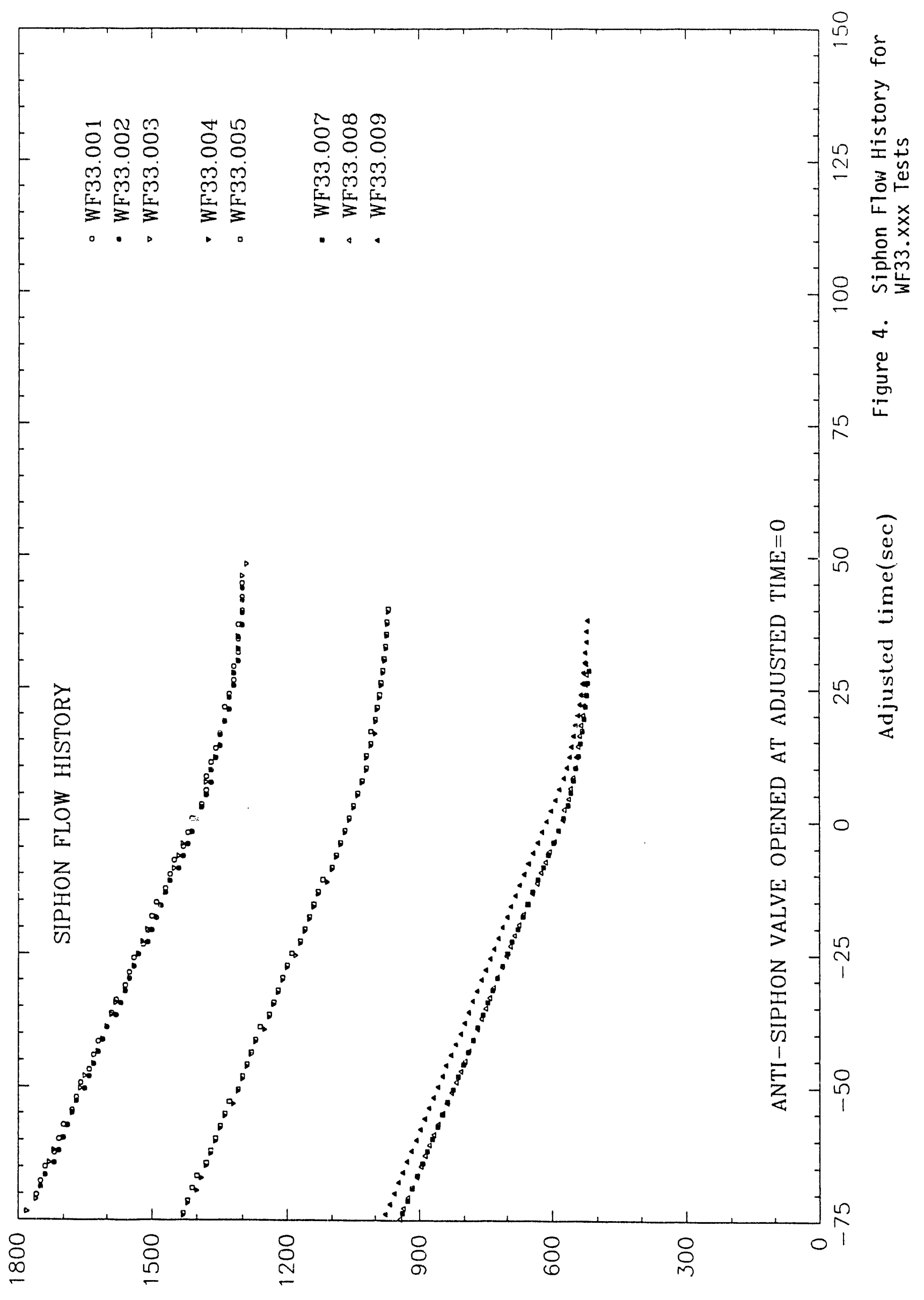

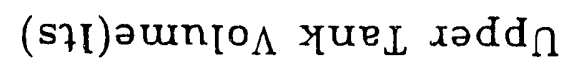




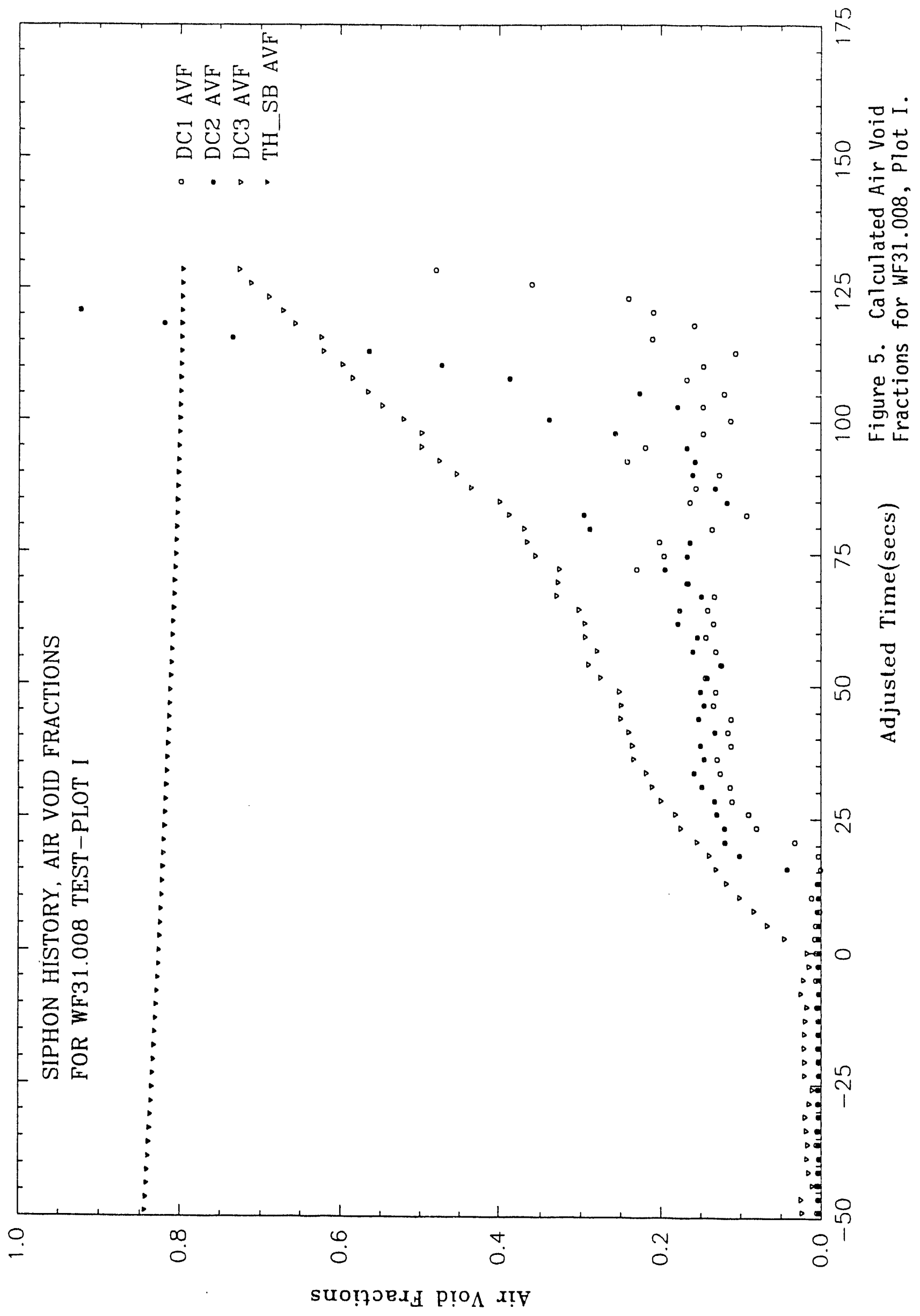




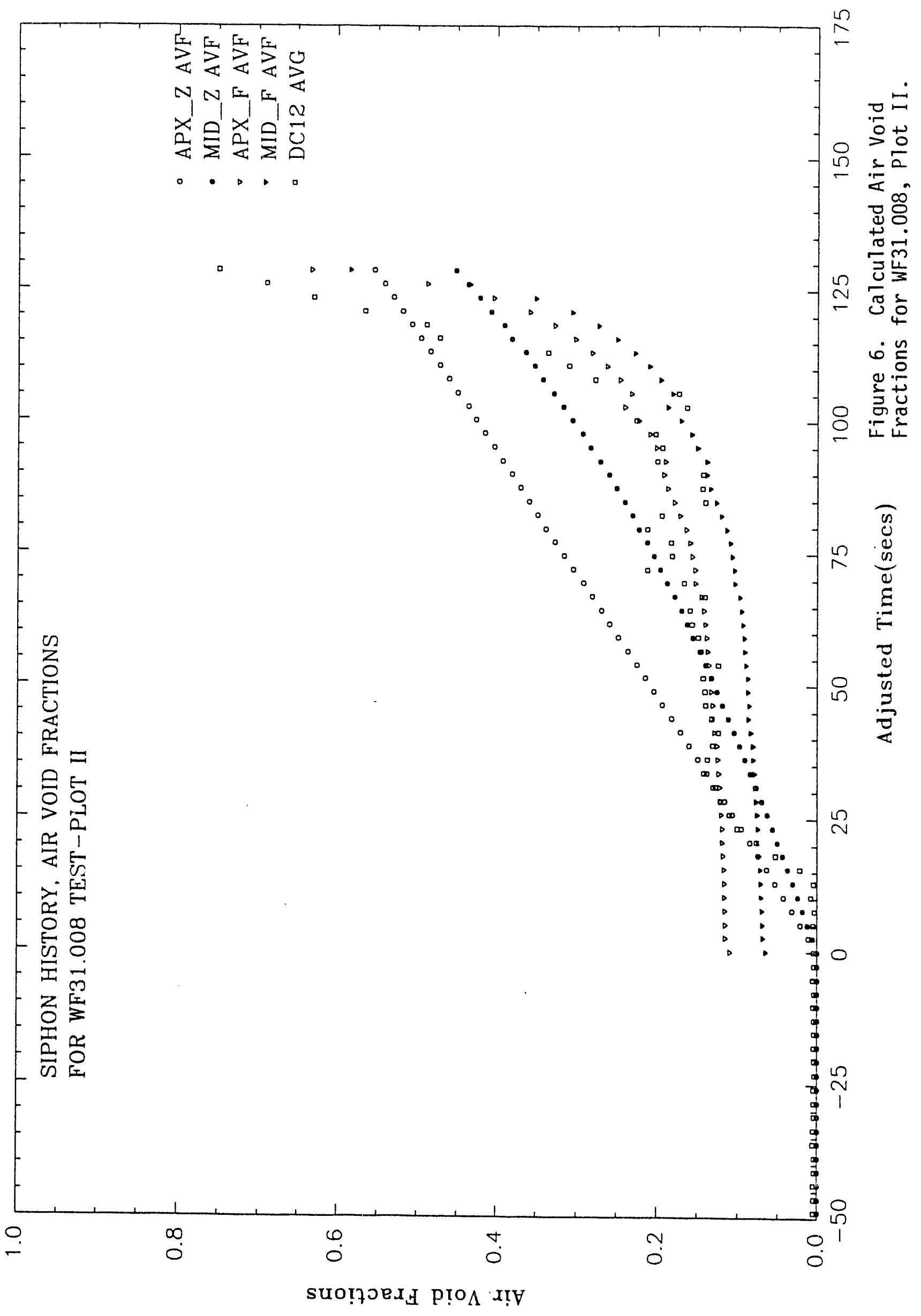




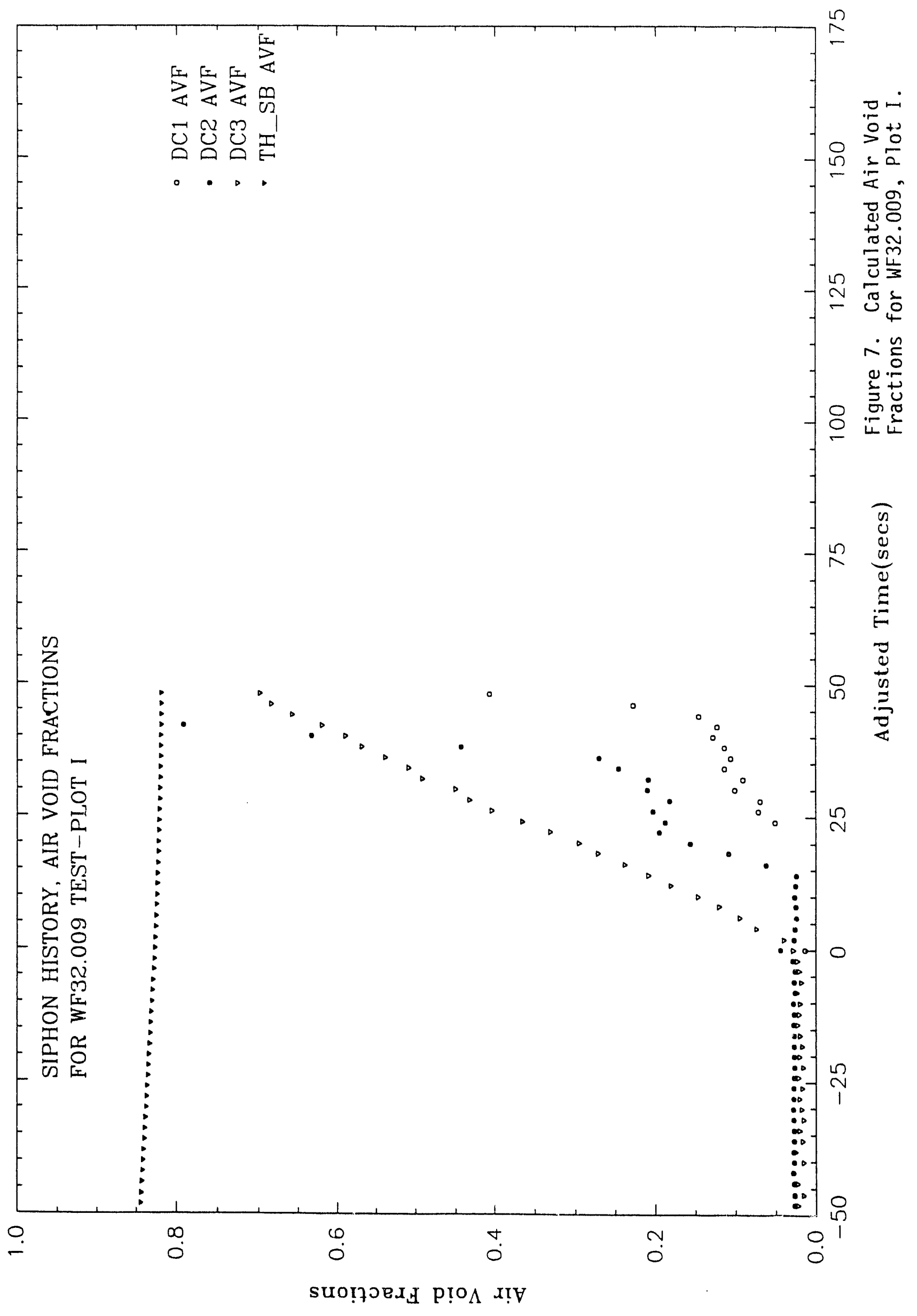




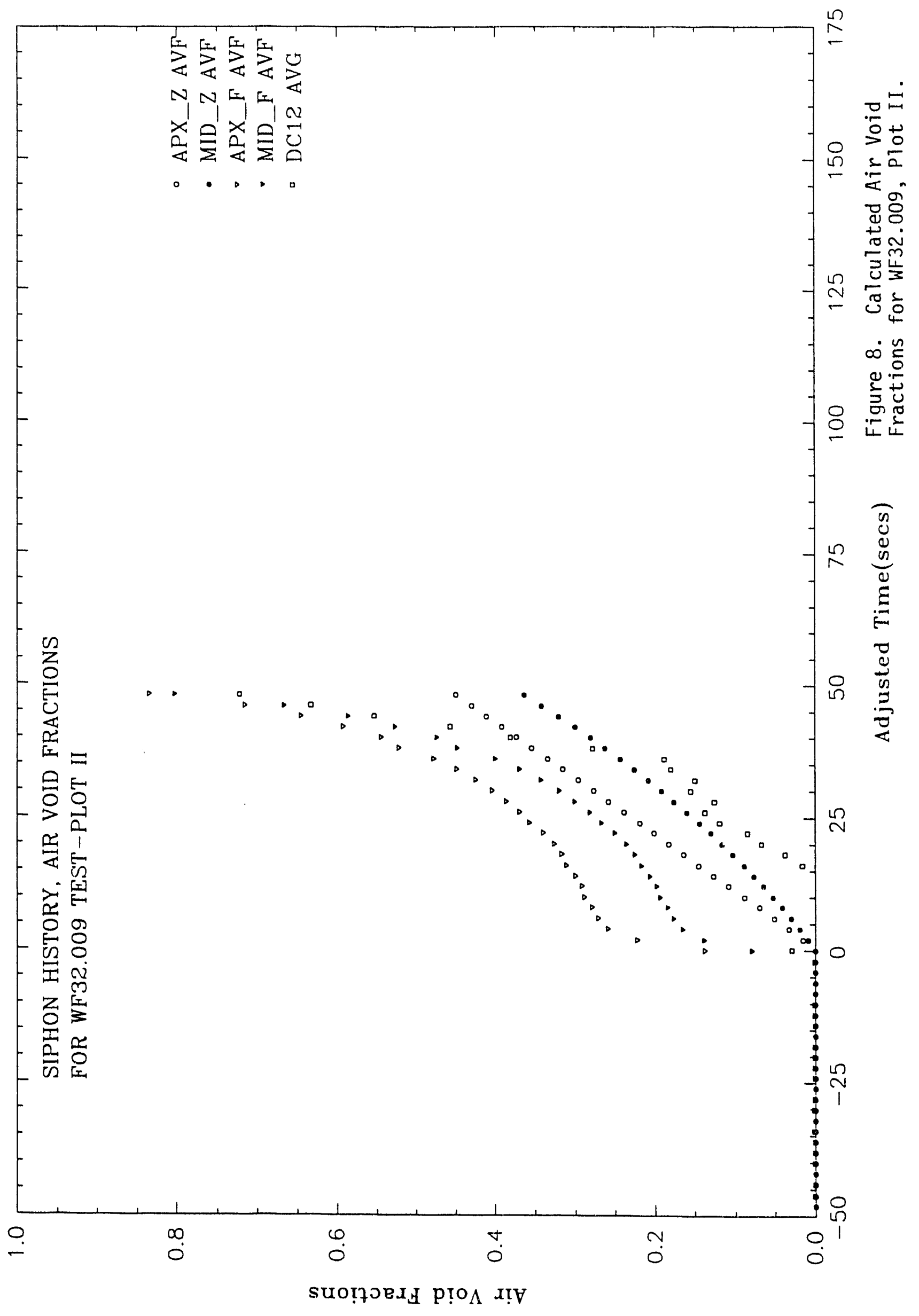




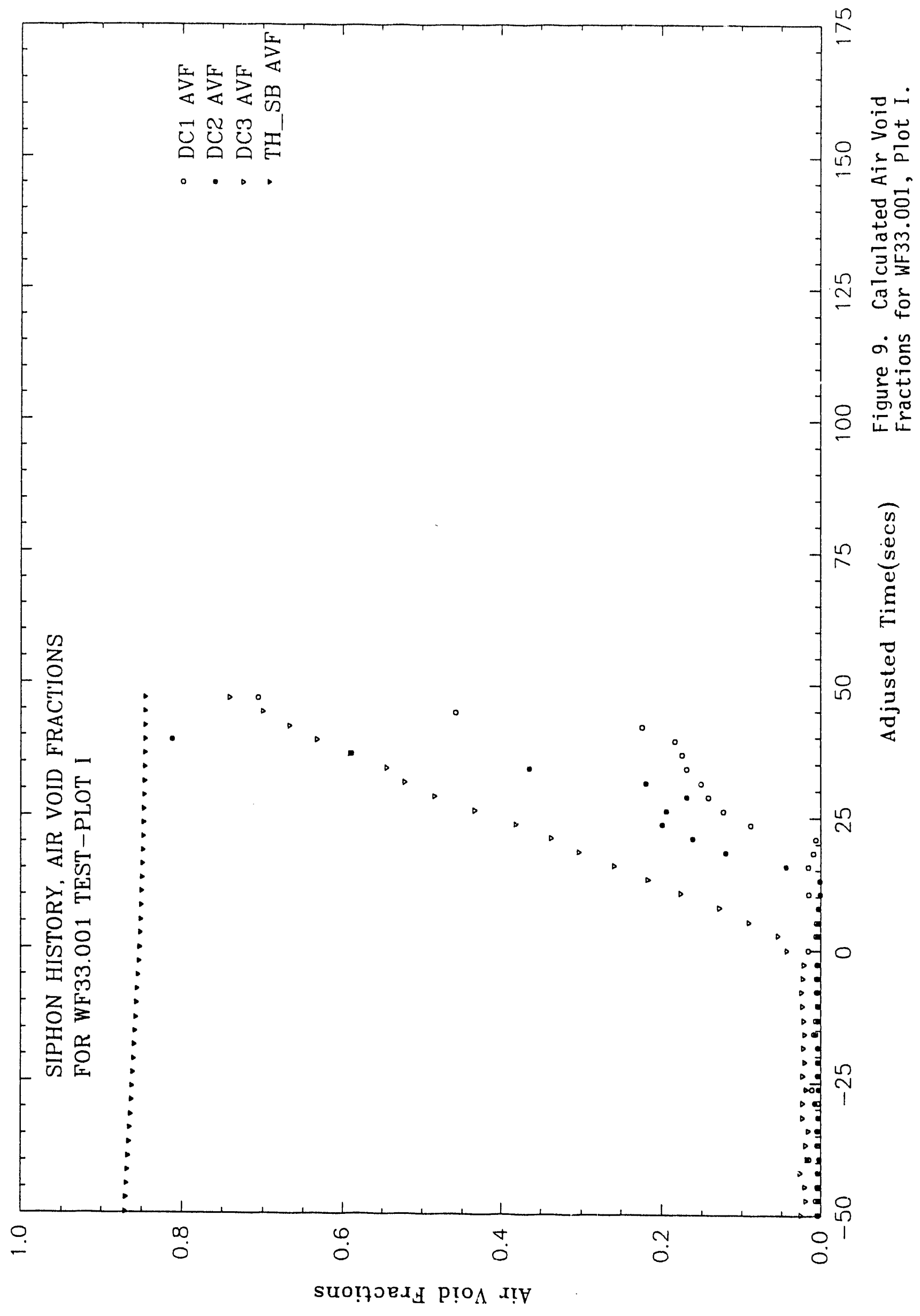




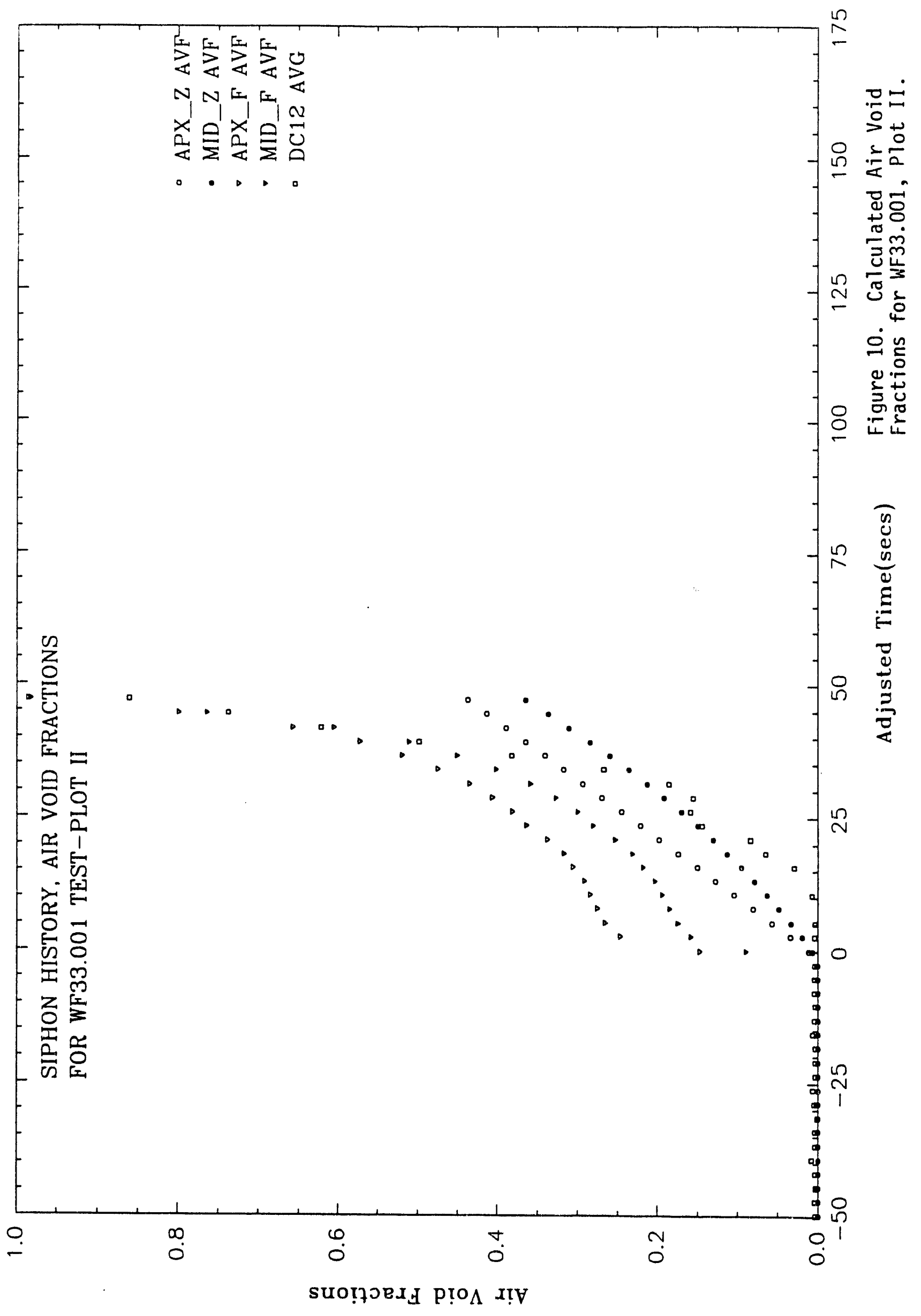


Point plotting on all figures was stopped at the time we believe the siphon was completely broken. Notice that the breaktimes seem to fall along a straight line locus. A few of the plotted test runs seem to have lasted significantly longer than the other identical runs, WF 31.005 on Figure 2 for example. such overruns are probably due to a misidentification of the time at which the siphon broke. The siphon water flow never stops abruptly; it always slows gradually just before stopping and then reverses. Since our turbine meter output reads positive for flow either way, picking the siphon break time can be a bit tricky.

Figures 5 through 10 present some "ideal" calculated air void fractions for one of the test from each of the three sets of runs depicted on Figures 2,3 and 4 . There are two plots, labeled Plot I and Plot II, for each test run.

Plot I shows the air void fraction based on the three differential pressure measurements. DC3 spans the apex to discharge; $D C 2$ and $D C l$ span a 6-foot length along the downcomer with DC2 located just above DCl. All these air void fractions were calculated as if the dp transmitter were measuring a static system, i.e., no friction loss corrections were attempted. Therefore, the small air void fraction values before adjusted time zero are false. However they do indicate the single-phase friction and allow readers to apply their own "windage" corrections to the void fraction values after adjusted time zero.

The points on Plot I labeled TH SB are theoretical void fractions to break the siphon. Those values are based on the ratio of the upcomer lift to the downcomer fall at no flow conditions.

Notice that for all three Plot I's, Figures 5, 7 and 9, the DCl and DC2 values remain near zero for the 15 to 20 seconds that it takes for the bubble front to reach their elevation. The DC2 values increase first since that dp transducer is above the DCl dp transducer. The scatter in the $D C 1$ and $D C 2$ values is due to the chaotic nature of the two phase flow. Remember each of the plotted points represents 5 averaged values over a 1 to 2 second period therefore, the instantaneous void fractions jump around even more than the plotted values. Also notice that the DCl and DC2 values become very large just before the siphon breaks. That increase means that a water fall front passed the measuring points.

The DC3 values, which come from the dp measurements spanning the entire downcomer, increase immediately and increase much more smoothly than the DCl and DC2 values. Also, the DC3 calculated air void fraction gets close to the theoretical air void fraction required to break the siphon but always stays a tenth or so below it. That observation has held for all the test runs to date. 
The Plot II's, Figures 6,8 and 10 , show further attempts to rationalize the test results by other simply calculated air void fractions. DC12 is just the arithmetic average of the DC1 and DC2 values on the associated Plot I. Those values still show a lot of scatter but they are smoother than either the DC1 or DC2 values.

The APX $Z$ and $A P X F$ values were calculated by assuming zero air sweepoint and full air sweepoint at the apex pressure. The zero air sweepoint calculation accumulates all the in-flow air, corrects its density to the apex pressure (typically some $30 \mathrm{kPa}$ below atmospheric pressure), and spreads it uniformly over the entire downcomer pipe volume (some $0.13 \mathrm{~m}^{3}$ ). The full sweepoint calculation is simply the ratio of the pressure corrected volumetric air flow to the total volumetric air and water flow. Note that the APX_F values rise quickly and then level-off, particularly on Figure 6. That pattern means the air inflow conditions remain quite constant until the water flow starts to decrease just before the siphon breaks.

The MID_Z and MID_F air void fraction values were based on the arithmetic average of the apex and discharge pressure. The zero and full sweepoint assumptions were the same as for the apex air void fraction calculations. We have not developed a satisfactory explanation for why the APX $z$ values rise rather Iinearly while the MID_Z valves bow upwards. We developed the zero and ful.I sweepoint concepts in hopes of bracketing siphon breaker performance. But, obviously that hasn't happened. We just don't know why these several air void fractions are always so much lower that the theoretical value required to break the siphon.

\section{FUTURE WORK}

As soon as we get our system modelad successfully on RELAP we will compare a variety of test and calculated parameters to decide just how well RELAP can predict siphon breaker performance. And, we will continue to try to rationalize the test results from all test runs.

We expect to have a final report written by october, 1991. 
December 20, 1991

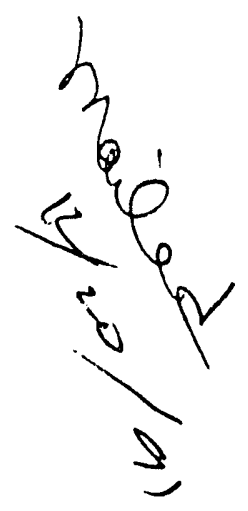

Dr. Thomas J. Dolan

EG\&G Idaho, Inc.

P. O. Box 1625, MS -2516

Idaho Falls, ID 83415

Dear Tom:

This letter is a request for an extension of the final report due date on the Siphon Breaker under contract no. DE-FG07-90ER12820.

The principal reason for this request is that we still cannot provide any theoretical comparison for the Siphon Breaker performance data. We have encountered a long string of problems with the RELAP code and no one has been able to get even a simple siphon flow model to run to completion. These code problems are so severe and so tangled that we are abandoning RELAP, at least for awhile, and going to try to upgrade the code we wrote some 15 years ago.

The graduate student working on this phase of the project, John Shatford, has been working full time at CSA, Inc. in Idaho Falls so our problem doesn't get much time devoted to it. John is a good student and good with computer codes, but he isn't in any position to fix RELAP. We have had a number of consultations with EG\&G's RELAP experts but so far "no joy."

All the experimental runs have been completed and the data is at least 98 percent reduced. We could put it all together as a final report without any comparison to the theoretical model but that's a poor last resort.

ISU would prefer to have a contract extension with no additional funds rather than closing the contract but still have a final report obligation. If that cannot be accomplished, please let me know.

very truly yours,

D. T. Neill, P.E., Professor College of Engineering

DTN : $1 \mathbf{k}$ 

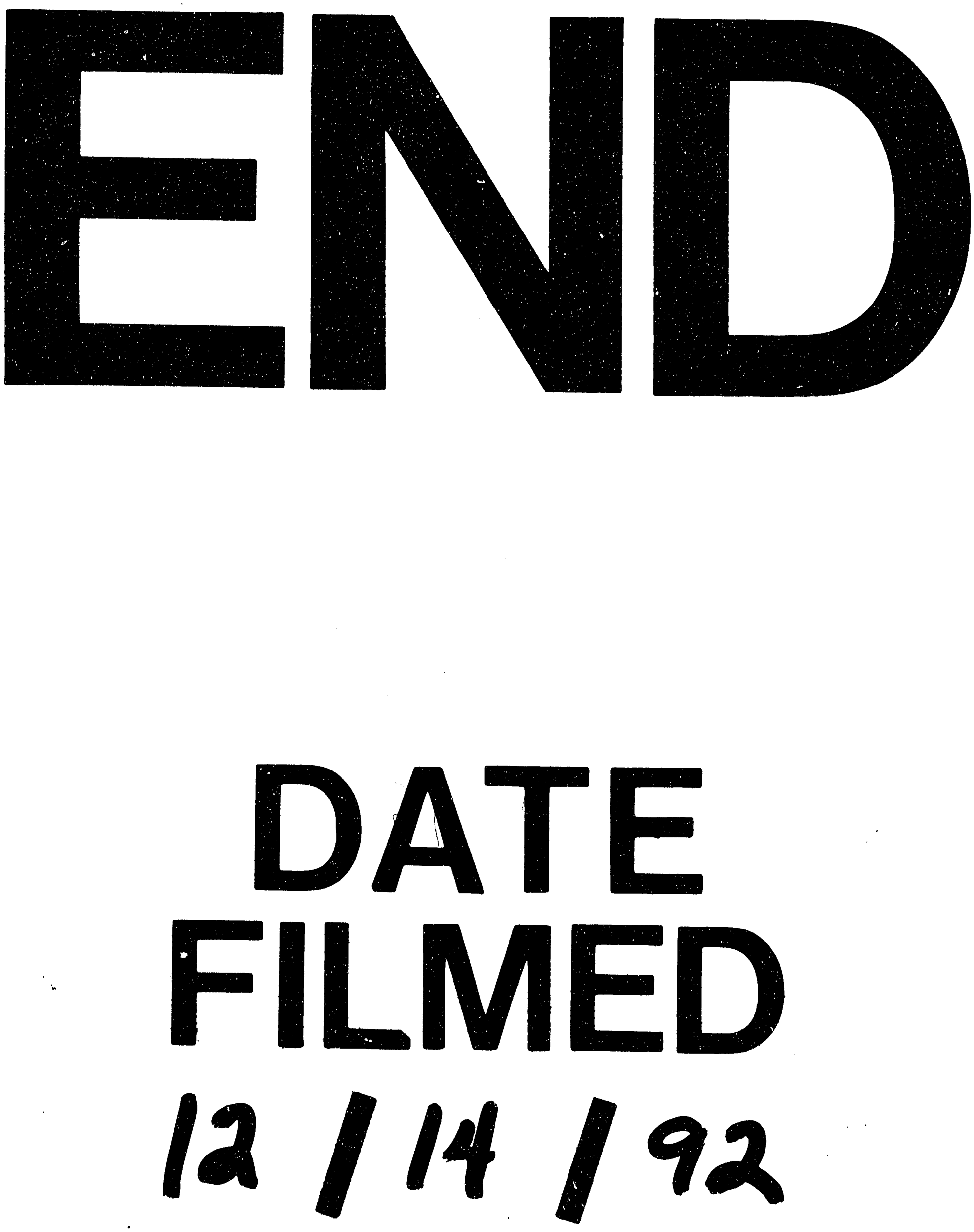
